\title{
AVALIAÇÃO DO EFEITO DE PREBIÓTICOS (MOS), PROBIÓTICOS (Bacillus licheniformis e Bacillus subtilis)E PROMOTOR DE CRESCIMENTO NA ALIMENTAÇÃO DE FRANGOS DE CORTE
}

\section{(Evaluation of the effect of prebiotics (MOS), probiotics (Bacillus licheniformis and Bacillus sibtillis) and growth promoter in broiler diets)}

FLEMMING, J.S.; FREITAS,R.J.S.

Programa de Pós Graduação em Tecnologia de Alimentos, UFPR.

RESUMO - Um experimento com 2400 aves foi realizado para comparar o efeito do uso de probiótico (Bacillus licheniformis e Bacillus subtilis), probiótico mais mananoligossacarídeos (MOS), promotor de crescimento (avilamicina) e uma dieta controle sem aditivos. As dietas básicas eram constituídas por milho e farelo de soja. Foi utilizado um delineamento inteiramente casualizado e os dados obtidos avaliados pela análise da variância e as médias comparadas pelo teste de Tukey ao nível de $5 \%$. Os parâmetros analisados foram ganho de peso, consumo de ração, conversão alimentar e mortalidade. Concluiu-se que na primeira semana o probiótico e o MOS apresentaram um ganho de peso significativamente melhor que os demais grupos. A conversão alimentar do probiótico na primeira semana foi melhor do que a do promotor de crescimento $(p<0,05)$, não diferindo da inclusão de MOS ou da dieta controle. No período total a inclusão do probiótico, de MOS e de promotor de crescimento apresentou melhor ganho de peso do que o controle.

Palavras-chave: Frangos de corte, promotores de crescimento, probióticos, prebióticos.

ABSTRACT - A study with 2,400 broilers was carried out to compare the effect of probiotics, (Bacillus licheniformis and Bacillus subtilis) probiotics plus mananoligosaccharides (MOS), or growth promoter (Avilamycin) and a control diet without aditives. Diets were based on corn and soybean meal. A completely randomized experimental design was used, and the data were evaluated by analysis of variance and test of Tukey at a level of $5 \%$. The following parameters were measured: feed intake, daily weight gain, feed conversion ratio, and mortality. It was concluded that the effect of the inclusion of probiotics and MOS in the starter diets was significantly higher for the weight gain than the other groups. The feed ratio was significantly higher at the first week as compared to the inclusion of MOS, or to the growth promoter and the control diet. In the full period the effect of the inclusion of probiotics, MOS and growth promoter was significantly higher for the weight gain than the control diet.

Key-words: Broiler diets, alternative growth promoters, probiotics, prebiotics.

\section{Introdução}

As condições de eubiose em frangos de corte podem ser alteradas por fatores mais variados possíveis como estresse, enterites ou parasitoses, determinando a exacerbação de microorganismos indesejáveis e um desequilíbrio do meio intestinal com efeitos nocivos na saúde animal e na produção (GARLICH, 1999; SILVA, 2000).

A manutenção da flora desejável tem sido há algum tempo obtida com o uso de promotores de crescimento, os quais deprimem os microorganismos considerados indesejáveis e proporcionam um meio favorável para aqueles considerados desejáveis. Fatores como o aparecimento de microorganismos resistentes pelo uso de promotores de crescimento antibióticos têm se tornado freqüentes e determinando medidas duras por parte das autoridades governamentais da Comunidade Européia e de outros países (BOLDUAN, 1999).

Setores da saúde pública do Brasil têm se manifestado contra os antibióticos e a sua proibição em rações é eminente, seguindo a 
tendência mundial e obedecendo às normas internacionais para o banimento completo dos promotores de crescimento previsto para 2006 (MILTENBURG, 2000).

Os transtornos entéricos dos animais associados à proibição do uso de promotores de crescimento levaram os pesquisadores a desenvolver alternativas, e dentre elas uma das mais viáveis é a cultura microorganismos desejáveis, que povoem o tubo digestivo, associada a fatores que favoreçam a multiplicação desses, proporcionando uma condição de equilíbrio. Os microorganismos capazes de se multiplicar e se adaptar rapidamente ao meio intestinal da maioria dos animais e ainda deprimir a proliferação daqueles considerados indesejáveis, são os pertencentes ao grupo dos probióticos e os agentes favorecedores à instalação dos probióticos no meio intestinal são os prebióticos.

Os prebióticos do tipo mananoligossacarídeos (MOS) são os de uso freqüente na indústria de rações, podendo ser utilizados como nutrientes pelas bactérias eutróficas, e alguns autores atribuem aumentos na retenção de minerais e uma melhor mineralização dos ossos quando suplementados a dietas de aves (BRADLEY e SAVAGE, 1994; MARTIN, 1994).

À medida que as bactérias probióticas e MOS são administrados, a condição de eubiose se torna permanente impossibilitando 0 estabelecimento de Escherichia coli, Clostridium sp, Salmonella $s p$, entre outros, aumentando o número de bactérias benéficas produtoras de ácido orgânicos como lático, acético e butírico (OYOFO et al., 1989; ITO et al., 2004).

Os probióticos e prebióticos são produtos inovadores, naturais, estabilizantes da flora intestinal agindo como melhoradores da saúde animal; aumentam o aproveitamento das proteínas, aminoácidos e energia da dieta; melhoram a atividade da fitase bacteriana; reduzem a mortalidade embrionária; aumentam a produção de ovos e o número de ovos férteis em matrizes. Também reduzem o aparecimento de neoplasias melhorando a atividade imunológica das aves. O uso contínuo de probióticos e prebióticos permite a redução de resíduos químicos em carcaça, o controle de salmoneloses, a redução de colesterol e a imunoestimulação, potencializando a produção e os programas sanitários como as vacinações em aves e em outros animais de interesse econômico (MARTIN, 1994).

O presente trabalho teve como objetivo avaliar o desempenho zootécnico de frangos de corte alimentados com dietas contendo probióticos, prebióticos, e ainda os efeitos das associações desses produtos, buscando uma resposta pelo seu efeito associado ou simbiótico comparando a um antibiótico promotor de crescimento e um controle negativo (sem drogas).

\section{Material e Métodos}

O experimento foi realizado na granja experimental da Cooperativa Agrícola Consolata - Copacol, localizada no município de Cafelândia, Oeste do Paraná. Foi utilizado um aviário experimental construído segundo os padrões empregados na integração avícola. As condições de manejo de ração, água, densidade de aves e demais seguiram as normas da empresa.

Foram utilizados 4 tratamentos com 6 repetições por tratamento. $O$ delineamento utilizado foi inteiramente casualizado. Foram utilizados o probiótico Bacillus licheniformis e Bacillus subtilis, um prebiótico (MOS) e um antibiótico promotor de crescimento (avilamicina). Os tratamentos foram: T1controle negativo, sem aditivos; T2- controle positivo, ração acrescida de promotor de crescimento (10 g/t de ração); T3- ração sem promotor de crescimento e acrescida do probiótico (1 kg probiótico/t de ração); T4- ração sem promotor de crescimento e acrescida de probiótico mais prebiótico ( $1 \mathrm{~kg}$ de probiótico/ tonelada mais $0,5 \mathrm{MOS} /$ tonelada de ração). $\mathrm{O}$ experimento utilizou 2400 frangos da linhagem comercial Ross, machos, divididos igualmente em 24 celas. A ração utilizada era isonutritiva e à base de milho e farelo de soja. As aves foram abatidas aos 42 dias de idade.

O probiótico continha Bacillus licheniformis e Bacillus subtilis com uma concentração mínima de $3,2 \times 10^{9}$ de esporos viáveis por $\mathrm{kg}$ do produto. Os microorganismos foram analisados antes e após a mistura à ração pelo 
Avaliação do efeito de prebióticos (mos), probióticos (Bacillus licheniformis e Bacillus subtilis) e promotor de...

Laboratório Avipa - Campinas - SP.

A análise estatística dos resultados zootécnicos: peso acumulado (GP), consumo de ração $(\mathrm{CR})$, conversão alimentar (CA), e Fator de Eficiência Europeu (EEF), foram obtidos ao longo do experimento por pesagens semanais e processados pelo programa STAT (versão 2.0) (1992), sendo as médias dos tratamentos, para as diferentes variáveis, comparadas através do teste de Tukey, com 95\% de confiabilidade $(p<0,05)$.

\section{Resultados e Discussão}

Os resultados do desempenho zootécnico das aves foram avaliados semanalmente e estão apresentados nas TABELAS 1 a 4.
Semanas 1 e 2: Os resultados estão demonstrados na TABELA 1. Na semana 1 (1 a 7 dias) a utilização do probiótico de forma isolada conferiu um ganho de peso significativamente melhor do que os tratamentos controle e com promotor de crescimento, não diferindo da associação com o prebiótico. Na conversão alimentar, que resume a relação consumo e ganho de peso, constatou-se uma diferença significativa, demonstrando que o probiótico apresentou resultado melhor do que o promotor de crescimento $(p<0,05)$, não diferindo contudo dos grupos controle e associação do prebiótico com o probiótico.

TABELA 1 - RESULTADOS ZOOTÉCNICOS DA ADIÇÃO DE PROBIÓTICO ASSOCIADO OU NÃO A PREBIÓTICO E DE UM PROMOTOR DE CRESCIMENTO À DIETA DE FRANGOS DE CORTE NO ESTÁGIO DE 1 A 14 DIAS DE IDADE. CAFELÂNDIA -PR. ( $N$ = 2400). 2004.

\begin{tabular}{lcccccc}
\hline \multirow{2}{*}{ TRATAMENTOS } & \multicolumn{3}{c}{ Parâmetros de 1 a 7 dias } & \multicolumn{3}{c}{ Parâmetros de 8 a 14 dias } \\
\cline { 2 - 7 } & $\mathrm{GP}(\mathrm{g})$ & $\mathrm{CR}(\mathrm{g})$ & $\mathrm{CA}(\mathrm{g} / \mathrm{g})$ & $\mathrm{GP}(\mathrm{g})$ & $\mathrm{CR}(\mathrm{g})$ & $\mathrm{CA}(\mathrm{g} / \mathrm{g})$ \\
\hline T1 (negativo) & $154,76^{\mathrm{a}}$ & 159,40 & $1,03^{\mathrm{ab}}$ & $369,4^{\mathrm{b}}$ & $436,10^{\mathrm{ab}}$ & 1,23 \\
T2 (antibiótico) & $155,48^{\mathrm{a}}$ & 167,92 & $1,08^{\mathrm{b}}$ & $370,6^{\mathrm{b}}$ & $428,46^{\mathrm{b}}$ & 1,15 \\
T3 ( probiótico) & $163,64^{\mathrm{b}}$ & 153,82 & $0,94^{\mathrm{a}}$ & $396,7^{\mathrm{a}}$ & $468,10^{\mathrm{a}}$ & 1,18 \\
T4 (probiót.+ prebiótico) & $157,57^{\mathrm{ab}}$ & 154,42 & $0,98^{\mathrm{ab}}$ & $374,7^{\mathrm{b}}$ & $450,10^{\mathrm{ab}}$ & 1,20 \\
\hline
\end{tabular}

NOTA: Médias seguidas da mesma letra não diferem entre si significativamente ao nível de $5 \%$ pelo teste de Tukey.

$\mathrm{GP}=$ ganho de peso, $\mathrm{CR}=$ consumo de ração e $\mathrm{CA}=$ conversão alimentar.

Na semana 2 (8 a 14 dias), o probiótico apresentou um ganho de peso significativamente melhor do que os tratamentos controle, com antibiótico e a associação probiótico mais prebiótico. Quanto ao ganho de peso, o grupo com probiótico foi significativamente melhor do que o controle não diferindo dos demais tratamentos. O maior consumo de ração foi o tratamento com a associação prebiótico mais probiótico e entre os demais não houve diferença.

Semanas 3 e 4: Na semana 3 (15 a 21 dias), o probiótico apresentou um ganho de peso significativamente melhor do que o controle, não diferindo entretanto dos demais tratamentos. O menor consumo de ração foi o tratamento controle, e os demais não diferiram entre si. Na semana 4 (22 a 28 dias), o probiótico e o promotor de crescimento conferiram um melhor ganho de peso que o grupo controle, não diferindo da associação de ambos (T4). A associação probiótico mais prebiótico consumiu significativamente menos ração que o grupo controle e o probiótico, não diferindo do promotor de crescimento (TABELA 2). 
TABELA 2 - RESULTADOS ZOOTÉCNICOS DA ADIÇÃO DE PROBIÓTICO ASSOCIADO OU NÃO A PREBIÓTICO E DE UM PROMOTOR DE CRESCIMENTO À DIETA DE FRANGOS DE CORTE NO ESTÁGIO DE 15 A 28 DIAS DE IDADE. CAFELÂNDIA -PR. ( $N=2400) .2004$.

\begin{tabular}{lcccccc}
\hline \multirow{2}{*}{ TRATAMENTOS } & \multicolumn{3}{c}{ Parâmetros de 15 a 21 dias } & \multicolumn{3}{c}{ Parâmetros de 22 a 28 dias } \\
\cline { 2 - 7 } & $\mathrm{GP}(\mathrm{g})$ & $\mathrm{CR}(\mathrm{g})$ & $\mathrm{CA}(\mathrm{g} / \mathrm{g})$ & $\mathrm{GP}(\mathrm{g})$ & $\mathrm{CR}(\mathrm{g})$ & $\mathrm{CA}(\mathrm{g} / \mathrm{g})$ \\
\hline T1 (negativo) & $770,8^{\mathrm{b}}$ & 1140,78 & 1,48 & $1298,0^{\mathrm{b}}$ & $2167,64^{\mathrm{a}}$ & 1,67 \\
T2 (antibiótico) & $777,5^{\mathrm{ab}}$ & 1142,92 & 1,47 & $1331,4^{\mathrm{a}}$ & $2114,24^{\mathrm{ab}}$ & 1,60 \\
T3 (probiótico) & $814,2^{\mathrm{a}}$ & 1188,73 & 1,46 & $1340,4^{\mathrm{a}}$ & $2251,87^{\mathrm{a}}$ & 1,68 \\
T4 (probiót.+ prebiótico) & $797,7^{\mathrm{ab}}$ & 1180,59 & 1,48 & $1318,4^{\mathrm{ab}}$ & $2056,70^{\mathrm{b}}$ & 1,56 \\
\hline
\end{tabular}

NOTA: Médias seguidas da mesma letra não diferem entre si significativamente ao nível de $5 \%$ pelo teste de Tukey.

$\mathrm{GP}=$ ganho de peso, $\mathrm{CR}=$ consumo de ração e $\mathrm{CA}=$ conversão alimentar.

Semanas 5 e 6: Não foi constatada diferença significativa entre os tratamentos

no período de 29 a 42 dias de idade (TABELA 3).

TABELA 3 - RESULTADOS ZOOTÉCNICOS DA ADIÇÃO DE PROBIÓTICO ASSOCIADO OU NÃO A PREBIÓTICO E DE UM PROMOTOR DE CRESCIMENTO À DIETA DE FRANGOS DE CORTE NO ESTÁGIO DE 29 A 42 DIAS DE IDADE. CAFELÂNDIA -PR. (N = 2400). 2004.

\begin{tabular}{lcccccc}
\hline \multirow{2}{*}{ TRATAMENTOS } & \multicolumn{3}{c}{ Parâmetros de 29 a 35 dias } & \multicolumn{3}{c}{ Parâmetros de 35 a 42 dias } \\
\cline { 2 - 7 } & $\mathrm{GP}(\mathrm{g})$ & $\mathrm{CR}(\mathrm{g})$ & $\mathrm{CA}(\mathrm{g} / \mathrm{g})$ & $\mathrm{GP}(\mathrm{g})$ & $\mathrm{CR}(\mathrm{g})$ & $\mathrm{CA}(\mathrm{g} / \mathrm{g})$ \\
\hline T1 (negativo) & 1899,2 & 3342,59 & 1,76 & 2510,5 & 4569,11 & 1,82 \\
T2 (antibiótico) & 1911,4 & 3325,14 & 1,74 & 2494,8 & 4490,64 & 1,80 \\
T3 ( probiótico) & 1901,4 & 3346.46 & 1,76 & 2553,7 & 4596,70 & 1,80 \\
T4 (probiót.+ prebiótico) & 1903,4 & 3388,05 & 1,78 & 2512,4 & 4597,69 & 1,83 \\
\hline
\end{tabular}

NOTA: $G P=$ ganho de peso, $C R=$ consumo de ração e $C A=$ conversão alimentar.

\section{Resultados Acumulados (do início do experimento aos 42 dias de idade)}

Os resultados estão demonstrados na TABELA 4. No período total do experimento constataram-se diferenças significativas entre os tratamentos no parâmetro ganho de peso, apresentando o probiótico um resultado melhor que o controle, não diferindo contudo dos demais. Este resultado não se repetiu para os demais parâmetros testados.

TABELA 4 - RESULTADOS ZOOTÉCNICOS DA ADIÇÃO DE PROBIÓTICO ASSOCIADO OU NÃO A PREBIÓTICO E DE UM PROMOTOR DE CRESCIMENTO À DIETA DE FRANGOS DE CORTE DO INÍCIO A 42 DIAS DE IDADE. CAFELÂNDIA -PR. ( $N=2400) .2004$.

\begin{tabular}{lrccc}
\hline \multirow{2}{*}{ TRATAMENTOS } & \multicolumn{4}{c}{ Parâmetros } \\
\cline { 2 - 5 } T1 (negativo) & $\mathrm{GP}(\mathrm{g})$ & $\mathrm{CR}(\mathrm{g})$ & $\mathrm{CA}(\mathrm{g} / \mathrm{g})$ & EEF \\
\hline T2 (antibiótico) & $2510,54^{\mathrm{a}}$ & 4643,50 & 1,85 & 312,17 \\
T3 (probiótico) & $2494,86^{\mathrm{ab}}$ & 4590,74 & 1,84 & 320,68 \\
T4 (probiót.+ prebiótico) & $2553,79^{\mathrm{b}}$ & 4622,35 & 1,81 & 329,66 \\
\hline
\end{tabular}

NOTA: Médias seguidas da mesma letra não diferem entre si significativamente ao nível de $5 \%$ pelo teste de Tukey.

$\mathrm{GP}=$ ganho de peso, $\mathrm{CR}=$ consumo de ração e $\mathrm{CA}=$ conversão alimentar, $\mathrm{EEF}=$ fator de eficiência europeu. 
Avaliação do efeito de prebióticos (mos), probióticos (Bacillus licheniformis e Bacillus subtilis) e promotor de...

Os melhores resultados de ganho de peso e conversão alimentar apresentados pelo probiótico comparativamente aos grupos controle e antibiótico na fase inicial de vida, sugerem um melhor equilíbrio entre os microorganismos do probiótico (Bacillus licheniformis e Bacillus subtilis), flora eutrófica desejável e a flora residual indesejável. Efeitos similares foram encontrados por FERNANDEZ e CRESPO (2003), ao citarem efeitos positivos no ganho de peso e eficiência alimentar quando se utilizou probióticos em substituição a antibióticos de forma continuada na dieta. DIBNER et al. (1996) referem que o desenvolvimento do trato gastrintestinal das aves pode ser afetado por ingredientes presentes na dieta, incluindo antibióticos e bactérias probióticas, portanto, os efeito encontrados no estudo podem ser atribuídos à estabilidade da flora intestinal. SILVA (2000) descreve que a saúde intestinal das aves é proporcionada por microorganismos eutróficos e pode ser efetivada quando as bactérias multiplicamse mais rapidamente do que a sua eliminação pelo peristaltismo intestinal e são encontradas livres na luz intestinal, ou então se agregando a microorganismos que já estão aderidas à mucosa entérica.

ITO et al. (2004) descrevem que a partir dos três dias de vida das aves os microorganismos desejáveis como Lactobacillus e outros da microbiota normal do trato gastrintestinal são encontrados em grandes quantidades no meio intestinal. Porém a ocorrência de desafios maiores em situações de morbidade ambiental pode tornar a flora instável até a quinta semana de vida das aves (CANALLI et al., 1996). GASAWAY (1976) constatou que valores de $5 \%$ a $10 \%$ das necessidades energéticas podem sofrer a influência da ação dos microorganismos, principalmente na forma de ácidos graxos voláteis de curta cadeia. As bactérias benéficas teriam a capacidade de produzir esses ácidos a partir da fibra da dieta no intestino grosso, proporcionando desta forma uma economia na energia da dieta, justificando o melhor ganho de peso apresentado pelo tratamento com o probiótico. A presença de bactérias enteropatogênicas no trato intestinal com seus efeito danosos as aves é relatado por ITO et al. (2004).

ESHDAT et al. (1978) reportam que a ligação das bactérias patogênicas no intestino das aves é freqüentemente mediado pela ligação de lectinas bacterianas aos receptores contendo Dmanose e desta forma os mananoligossacarídeos podem ser utilizados para diminuir a colonização por bactérias indesejáveis. A associação de probióticos com o prebiótico tem como característica a diminuição e/ou inibição da colonização do trato gastrintestinal por microorganismos patógenos, ação esta que alguns autores atribuem como responsável por ganhos em parâmetros zooeconômicos quando são suplementados à dietas de aves (NEWMAN, 1994; SANTIN et al., 2001). Os probióticos são desenvolvidos visando a estabilização da flora eutrófica já nos primeiros dias de vida das aves, evitando o aparecimento de problemas entéricos por microorganismos oriundos do meio (DAY, 1992; REIG e ANESTO, 2002).

No presente estudo foi constatado de forma significativa $(p<0,05)$ durante 0 decorrer do experimento que os tratamentos com probiótico e prebiótico apresentaram resultados superiores ao controle e similares ou até melhores em alguns parâmetros do que o uso do promotor de crescimento.

\section{Conclusões}

Considerando-se as condições em que foi realizado o experimento, pode-se concluir que:

$\mathrm{Na}$ fase inicial de vida, o probiótico apresentou resultados significativos para ganho de peso (semanas 1 e 2) quando comparado ao controle e antibiótico.

A conversão alimentar para o probiótico foi significativamente melhor do que o antibiótico $(p<0,05)$ na primeira semana.

$\mathrm{Na}$ fase de crescimento, o probiótico, 
promotor de crescimento e a associação probiótico e Mananoligossacarídeos apresentaram melhor ganho de peso do que o controle, o qual por sua vez consumiu menos ração do que os demais $(\mathrm{p}<0,05)$.

No resultado acumulado (inicio ao abate com 42 dias), o probiótico apresentou os melhores resultados para ganho de peso $(p<0,05)$ em relação ao controle, não diferindo entretanto da associação de probiótico com prebiótico (MOS) e o antibiótico.

\section{REFERÊNCIAS}

BOLDUAN, G. Feeding weaner pigs without feed antibiotics. In: Biotecnology in the feed industry. Nottingham: Nottingham University Press, 1999. p. 223-230.

BRADLEY, G.T.; SAVAGE, T. F. Enhance utilization of dietary calcium, phosphorus, nitrogen and metabolizable energy in poults feed diet containing a yeast culture. Poultry Science, Champaign, n. 73, p. 124-127, 1994.

CANALLI, L.S.; FLEMMING, J.S.; MIRA, R.T.; BASILE, L.F. Alteração da microbiota intestinal de frangos de corte pela utilização de probiótico na alimentação. Revista do Setor de Ciências Agrárias, Curitiba, v. 15, n. 1, p. 125-132, 1996.

DAY, C.A. Competitive exclusion in poultry: a review. Worcestershire: Life Care Products, 1992. $18 \mathrm{p}$.

DIBNER, J.J.; KITCHEL, C.A; ATWELL, M.L. IVEY, E.J. The effect of dietary ingredients and age on the microscopic structure of the gastrointestinal tract in Poultry. Journal Applied Poultry Research, Champaign, n. 5, p. 70-77, 1996.

ESHDAT, Y.; OFEK, L.; SHARON, N. Isolation of manose especific lecitin from Escherichia coli and is role in the adherence of bacteria in the epithelial cells. Biochemical and Biophysical Research Communications, New York, v. 85, p. 1551-1559, 1978.
FERNANDEZ, J.; CRESPO, N. New avances in the application of probiotics. International Pig Topics, Driffield, v. 18, n. 7, p. 11-13, 2003.

GARLICH, J.D. Microbiologia do tracto intestinal aviar. In: CONGRESSO LATINOAMERICANO DE AVICULTURA. 16., 1999, Lima. Anais... Lima: 1999. p. $110-120$.

GASAWAY, W.C. Volatile fatty acids and metabolizable energy derived from cecal fermentation in willow. Comparative Biochemistry Physiology, New York, n. 53, p. 115-116, 1976.

ITO, N.M.K.; MIAJI, C.I.; LIMA, A E.; OKABAHASHI, S. Saúde gastrointestinal, manejo e medidas para controlar as enfermidades gastrointestinais. In: PRODUÇÃO DE FRANGOS DE CORTE, 2004, Campinas. Anais... Campinas: FACTA. 2004. p 206-260.

MARTIN, S.C. Potential for manipulating the gastrointestinal microflora: A review of recent progress. In : BIOTECNOLOGY IN THE FEED INDUSTRY OF ANNUAL SYMPOSIUM, 10., 1994, London. Proceedings... London: Nottingham University Press, 1994. p. 155-166.

MILTEMBURG, G. Promotores e aditivos de crescimento em Avicultura. In: CONFERENCIAAPINCO DE CIÊNCIA ETECNOLOGIAAVICOLAS, 2000, Campinas. Anais... Campinas: FACTA, 2000. p. 204-215.

NEWMAN, K. Mannanologosaccharides: Natural polynmers whith significant impact on the gastrointestinal microflora and the immune system. In: BIOTECNOLOGY IN THE FEED INDUSTRY OF ANNUAL SYMPOSIUM, 10., 1994, London. Proceedings... London: Nottingham University Press, 1994. p. 155-166.

OYOFO, B.A.; NORMAN, J.O.; MOLLENHAUER, C. Prevention of Salmonella thiphimurium colonization of broilers with D-mannose. Poultry Science, Champaign, n. 68, p. 357-1360. 1989.

REIG, A.L. C.; ANESTO, J.B. Prebióticos y probióticos una relación benefiosa. Revista Cubana de Alimentación y Nutrición, Havana, n. 16, p. 63-68, 2002.

SANTIN, E.; MAIORKA, A.; MACCARI, M. Performance and intestinal mucosa development of broiler chickens containing Saccharomyces cerevisae cell wall. Journal Applied Poultry Research, Champaign, n. 10, p. 236-244, 2001. 
SILVA, E.N. Probióticos e Prebióticos na Alimentação de Aves. In: CONFERENCIA APINCO DE CIÊNCIA E TECNOLOGIA AVICOLAS, 2000, Campinas. Anais... Campinas:

FACTA, 2000. p. 204-215.

Recebido para publicação: 14/04/2005 Aprovado:

\author{
$20 / 08 / 2005$
}

STAT 2.0. Sistema de análise estatística. Jaboticabal: UNESP. Polo Computacional do Departamento de Ciências Exatas, 1992. 